\title{
Stress Corrosion of Wrought Magnesium Base Alloys
}

\section{By Hugh L. Logan and Harold Hessing}

\begin{abstract}
The rates of corrosion of many metals and alloys are increased by the presence of tensile stresses in the materials. In order to determine the effect of tensile stress on the behavior of magnesium alloys exposed to corrosive media, stress-corrosion tests were made on several magnesium base alloys at two weather exposure sites, and in the laboratory by continuous immersion in a $\mathrm{NaCl}+\mathrm{K}_{2} \mathrm{CrO}_{4}$ solution and by intermittent immersion in a dilute $\mathrm{NaCl}$ solution.

The periods of time to failure of specimens exposed under tensile stress in the atmosphere at the National Bureau of Standards were less than those for the same materials exposed in a marine atmosphere at Hampton Roads, Va.

The M1 clad AZ31X-h sheet alloy proved more resistant to stress corrosion than bare AZ31X-h, AZ51X, or AZ61X sheet alloys and AZ80X extruded alloys.

Predictions of relative susceptibility of materials to stress corrosion from intermittent immersion laboratory tests in a 0.01 -percent $\mathrm{NaCl}$ solution were in good agreement with the results obtained from weather exposure tests at this Bureau.
\end{abstract}

\section{Introduction}

Early in World War II a number of welded airplane booms, constructed of AZ61X magnesium alloy sheet and extrusions were subjected to static loading until buckling occurred and were then stored in the open exposed to the weather. Subsequent examination revealed stress corrosion in the buckled areas.

Inasmuch as the Bureau of Aeronautics, Navy Department, was interested in the possibilities of the use of magnesium alloys in aircraft structures, it gave financial support to the National Bureau of Standards to study the resistance of various commercial wrought alloys to stress corrosion. The investigation was carried out with the specific purpose of determining the relative susceptibility of various alloys to stress corrosion, and whether a correlation could be established between the results of various laboratory tests and those of weather exposure tests.

\section{Materials and Methods of Test}

\section{Materials}

Seven wrought magnesium alloys were studied in this investigation. Four of these materials, the
M1, AZ31, AZ61, and AZ80 alloys had been used in this country in structural applications prior to the war. An AZ31 alloy clad with thin layers of the M1 alloy; an alloy designated as AZ51 and a zinc, zirconium alloy, designated by Dow as ZK60, all developed by the Dow Chemical Co. during the war, were also included in the study. The materials were supplied by the American Magnesium Corp. and the Dow Chemical Co. The ASTM and manufacturers' designations, and the nominal chemical compositions are given in table 1 .

Materials received from the Dow Chemical Co. generally had an oiled finish. After the sheet or extruded material had been machined into specimens the thickness was reduced approximately 0.002 in. by immersion in an aqueous solution containing $30 \mathrm{ml}$ of concentrated $\mathrm{HNO}_{3}$, and 10 $\mathrm{ml}$ of concentrated $\mathrm{H}_{2} \mathrm{SO}_{4}$ per liter.

Materials received from the American Magnesium Corp. had a chrome-pickled finish. They were machined into tensile specimens, and the chrome-pickle film was then removed by immersion in an aqueous solution containing $22.5 \mathrm{~g}$ of $\mathrm{Na}_{2} \mathrm{CO}_{3}$, and $15 \mathrm{~g}$ of $\mathrm{NaOH}$ per liter. 
TABLE 1. ASTM and manufacturers' designations, and nominal compositions a of the magnesium base alloys investigated

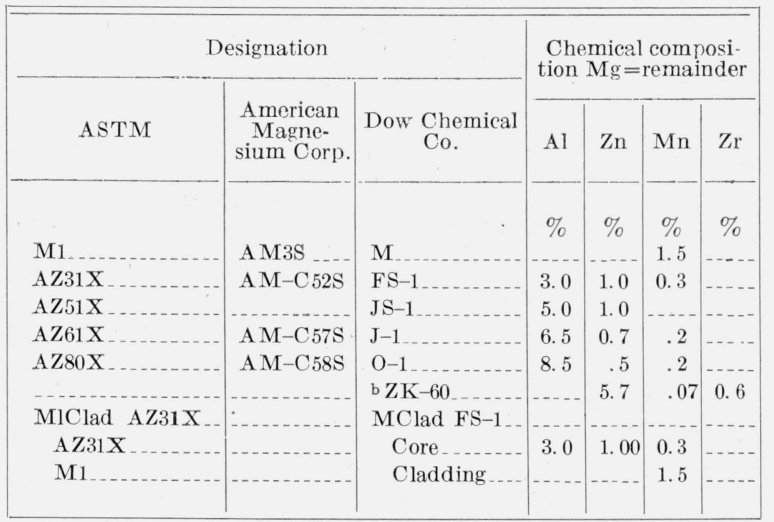

a Nominal compositions given are those prevailing at the time the materials were received for test. Analyses furnished by the manufacturers did not differ significantly from the above values.

b Composition determined by chemical and spectrochemical means at this Bureau

After the treatment to remove the chromepickle film or the outer layers of material, all of the specimens except the clad AZ31X-h material, whose thin cladding would have been seriously affected, were ground parallel to the long axes of the specimens, prior to testing, using number 400 Aloxite belts on a rubber backed wheel. The chemical and grinding treatments were used to obtain uniform surface conditions on specimens before exposure.

In general, the alloys supplied in sheet form were tested in each of two tempers, annealed (-a) and hardened by rolling $(-\mathrm{h})$, and also in two thicknesses 0.064 and 0.125 in. The extruded material (except the ZK-60 alloy) was supplied in two rectangular cross sections. The heattreatable extruded alloy AZ80X was supplied both in the as-extruded and in the extruded, heattreated and aged (HTA) conditions. The tensile properties of the sheet materials as received are given in tables 2,3 , and 4 . The sheet material was rolled by the usual manufacturing process, except that two lots of material (see table 4) were rolled by a special process developed by M. A. Hunter of Rensselaer Polytechnic Institute. The cross-sectional dimensions and tensile properties of the extruded materials are given in table 5 .

TABLE 2. Tensile properties of the AZ61X and M1 magnesium base sheet alloys and threshold stresses (as determined in the $\mathrm{NaCl}+\mathrm{K}_{2} \mathrm{CrO}_{4}$ solution) of the $A Z 61 X$ alloy

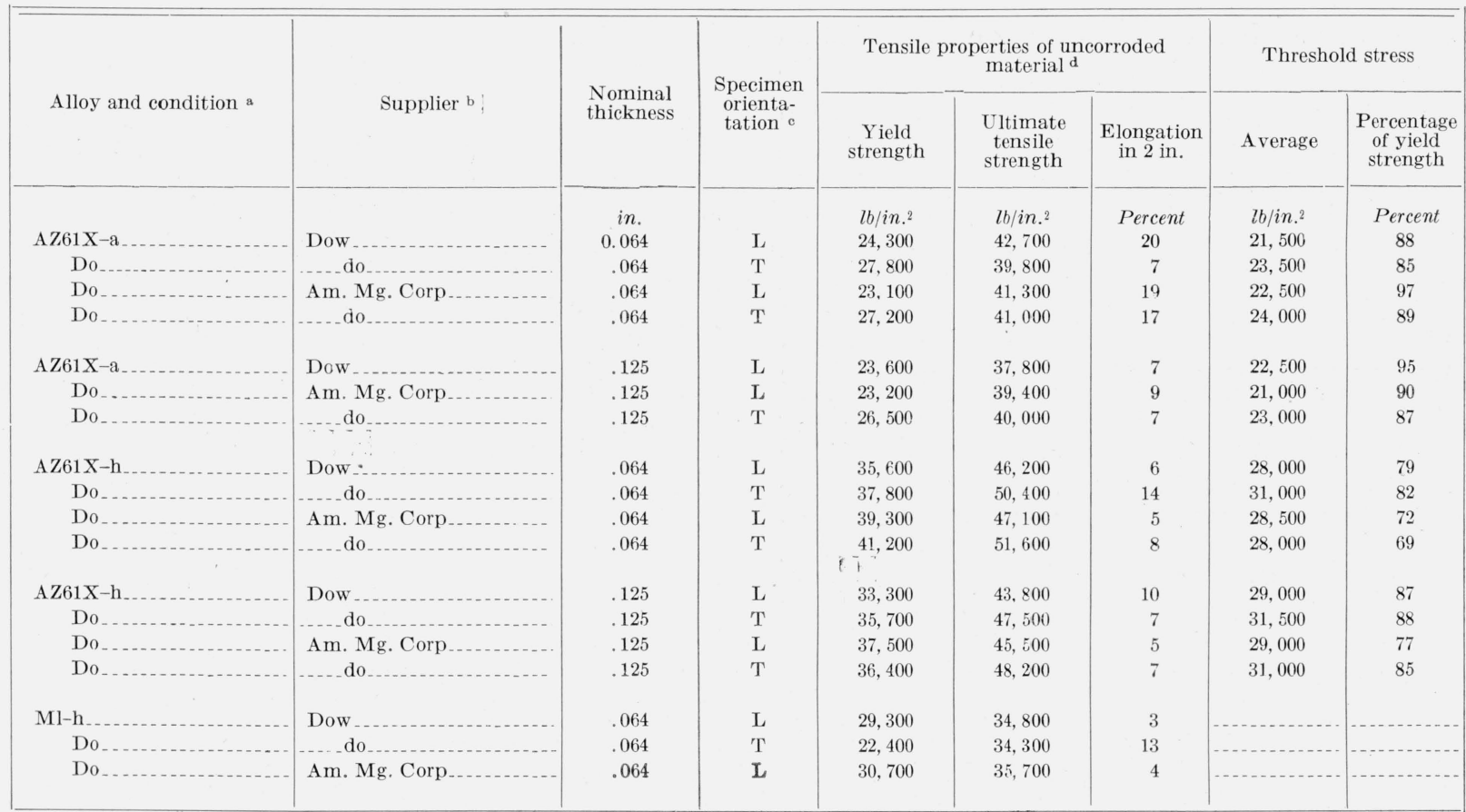

a "a" indicates annealed material; " $h$ " material hardened by rolling.

b Dow indicates Dow Chemical Co.; Am. Mg. Corp. indicates American Magnesium Corp.

- $\mathrm{L}$ and $\mathrm{T}$ designate, respectively, longitudinal and transverse specimens.

d Each value is the average of 5 or more determinations. 
TABLE 3. Tensile properties and threshold stresses (as determined in the $\mathrm{NaCl}+\mathrm{K}_{2} \mathrm{CrO}_{4}$ solution) of AZ31X magnesium base sheet alloy

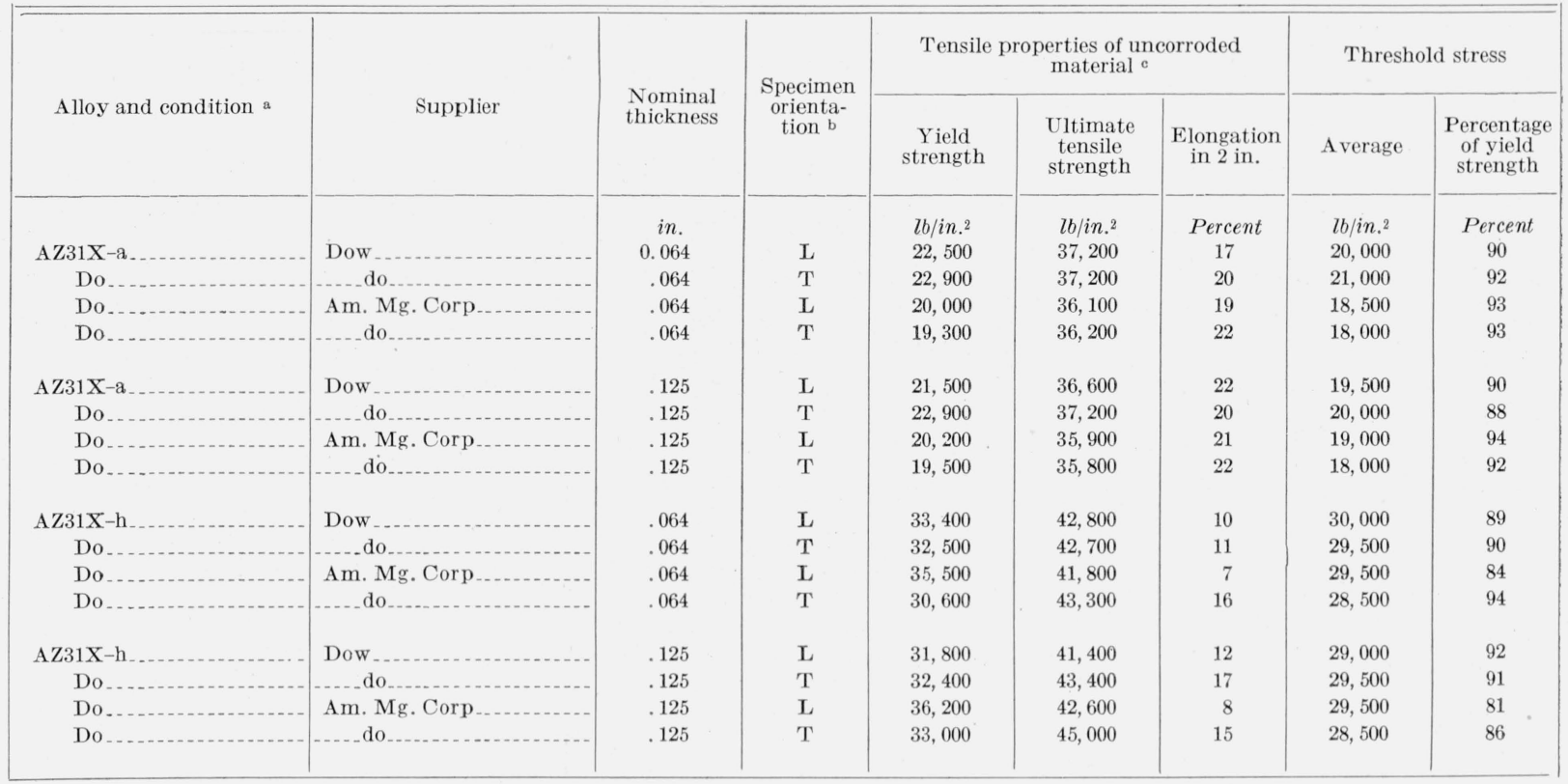

a "a" indicates annealed material; " $\mathrm{h}$ " material hardened by rolling.

b $\mathrm{L}$ and $\mathrm{T}$ designate, respectively, longitudinal and transverse specimens.

c Each value is the average of 5 or more determinations.

TABLE 4. Tensile properties and threshold stresses (as determined in the $\mathrm{NaCl}+\mathrm{K}_{2} \mathrm{CrO}_{4}$ solution) of the AZ51X-h and the AZ31X-h magnesium base sheet alloys 0.064 in. thick, rolled by two processes and supplied by the Dow Chemical Co.

\begin{tabular}{|c|c|c|c|c|c|c|}
\hline \multirow{2}{*}{ Alloy and condition } & \multirow{2}{*}{$\begin{array}{l}\text { Specimen } \\
\text { orienta- } \\
\text { tion }{ }^{a}\end{array}$} & \multicolumn{3}{|c|}{$\begin{array}{l}\text { Tensile properties of uncorroded } \\
\text { material } b\end{array}$} & \multicolumn{2}{|c|}{ Threshold stress } \\
\hline & & $\begin{array}{l}\text { Yield } \\
\text { strength }\end{array}$ & $\begin{array}{l}\text { Ultimate } \\
\text { tensile } \\
\text { strength }\end{array}$ & $\begin{array}{l}\text { Elongation } \\
\text { in } 2 \mathrm{in.}\end{array}$ & $\begin{array}{l}\text { Average } \\
\text { value }\end{array}$ & $\begin{array}{l}\text { Percentage } \\
\text { of yield } \\
\text { strength }\end{array}$ \\
\hline \multicolumn{7}{|c|}{ ROLLED BY THE STANDARD DOW PROCESS } \\
\hline $\begin{array}{l}\text { A Z } 51 X-h \\
\text { A Z } 51 X-h \\
\text { A Z31X-h } \\
\text { A Z31X-h }\end{array}$ & $\begin{array}{l}\mathrm{L} \\
\mathrm{T} \\
\mathrm{L} \\
\mathrm{T}\end{array}$ & $\begin{array}{l}l b / \text { in. }^{2} \\
34,800 \\
40,600 \\
32,900 \\
34,800\end{array}$ & $\begin{array}{l}l b / \text { in }^{2} \\
47,000 \\
50,600 \\
43,100 \\
44,700\end{array}$ & $\begin{array}{c}\text { Percent } \\
11 \\
15 \\
10 \\
12\end{array}$ & $\begin{array}{l}l b / \text { in }^{2} \\
34,000 \\
37,000 \\
29,000 \\
29,000\end{array}$ & $\begin{array}{l}\text { Percent } \\
98 \\
91 \\
88 \\
83\end{array}$ \\
\hline \multicolumn{7}{|c|}{ ROLLED BY THE HUNTER PROCESS } \\
\hline $\begin{array}{l}\text { A Z51X-h } \\
\text { A Z51X-h } \\
\text { A Z31X-h } \\
\text { A Z31X-h }\end{array}$ & $\begin{array}{l}\mathrm{L} \\
\mathrm{T} \\
\mathrm{L} \\
\mathrm{T}\end{array}$ & $\begin{array}{l}34,300 \\
39,200 \\
32,700 \\
34,200\end{array}$ & $\begin{array}{l}46,000 \\
49,300 \\
42,600 \\
44,000\end{array}$ & $\begin{array}{l}11 \\
12 \\
11 \\
18\end{array}$ & $\begin{array}{l}33,000 \\
36,500 \\
29,500 \\
31,500\end{array}$ & $\begin{array}{l}96 \\
93 \\
90 \\
92\end{array}$ \\
\hline
\end{tabular}

a $\mathrm{L}$ and $\mathrm{T}$ designate, respectively, longitudinal and transverse specimens

${ }^{b}$ Each value is the average of 5 or more determinations. 
TABLE 5. Tensile properties and threshold stresses (as determined in the $\mathrm{NaCl}+\mathrm{K}_{2} \mathrm{CrO}_{4}$ solution) of the $5.7-p e r c e n t$ zinc, 0.6-percent zirconium (Dow ZK-60), the $A Z 61 X$, and the $A Z 80 X$ magnesium base alloy extrusions

\begin{tabular}{|c|c|c|c|c|c|c|c|c|}
\hline \multirow{2}{*}{ Alloy and condition } & \multirow{2}{*}{ Supplier } & \multicolumn{2}{|c|}{ Nominal dimensions } & \multicolumn{3}{|c|}{$\begin{array}{l}\text { Tensile properties of uncorroded } \\
\text { material a }\end{array}$} & \multicolumn{2}{|c|}{ Threshold stress } \\
\hline & & Thickness & Width & $\begin{array}{l}\text { Yield } \\
\text { strength }\end{array}$ & $\begin{array}{l}\text { Ultimate } \\
\text { tensile } \\
\text { strength }\end{array}$ & $\begin{array}{l}\text { Elongation } \\
\text { in } 2 \text { in. }\end{array}$ & Average & $\begin{array}{l}\text { Percentage } \\
\text { of yield } \\
\text { strength }\end{array}$ \\
\hline \multicolumn{9}{|c|}{ TESTED AS EXTRUDED } \\
\hline $\mathrm{ZK}-60_{-}$ & Dow ... & $\begin{array}{l}\text { in } \\
1 / 16\end{array}$ & $\begin{array}{r}i n . \\
1\end{array}$ & $\begin{array}{l}l b / \text { ine. }^{2} \\
39,500\end{array}$ & $\begin{array}{l}l b / i n .2^{2} \\
50,000\end{array}$ & $\begin{array}{l}\text { Percent } \\
13\end{array}$ & $\begin{array}{l}l b / i n .^{2} \\
33,000\end{array}$ & $\begin{array}{l}\text { Percent } \\
\quad 84\end{array}$ \\
\hline $\mathrm{AZ} 61 \mathrm{X}$ & Dow & $1 / 16$ & $3 / 4$ & 25,800 & 43,900 & 12 & 23,500 & 91 \\
\hline Do $\ldots .$. & Am. Mg. Corp & $1 / 16$ & 1 & 29,500 & 42,900 & 16 & 27,500 & 87 \\
\hline Do .... & Dow & $1 / 8$ & $1 \frac{1 / 4}{4}$ & 26,900 & 44,800 & 17 & 23,500 & 87 \\
\hline Do_ ... & Am. Mg. Corp ... & $1 / 8$ & $1 \frac{1}{4}$ & 31,800 & 43,600 & 16 & 25,500 & 81 \\
\hline $\mathrm{AZ} 80 \mathrm{X}$ & Dow & $1 / 16$ & $3 / 4$ & 28,900 & 47,200 & 12 & 26,500 & 92 \\
\hline Do & Am. Mg. Corp & 1/16 & 1 & 29,900 & 46,800 & 17 & 25,000 & 84 \\
\hline Do $\ldots . .$. & Dow & $1 / 8$ & $1 \frac{1 / 4}{4}$ & 31,000 & 48,400 & 12 & 26,500 & 85 \\
\hline Do ............ & Am. Mg. Corp & $1 / 8$ & $11 / 4$ & 34,500 & 48,500 & 19 & 27,000 & 78 \\
\hline \multicolumn{9}{|c|}{ EXTRUDED, HEAT TREATED, AND AGED } \\
\hline A $Z 80 \mathrm{X}-\mathrm{HTA}$ & Dow & $1 / 16$ & $3 / 4$ & 34,200 & 49,000 & 7 & 32,500 & 95 \\
\hline Do & Am. Mg. Corp & $1 / 16$ & 1 & 29,000 & 49,200 & 13 & 27,500 & 95 \\
\hline Do & Dow & $1 / 8$ & $11 / 4$ & 37,200 & 49,600 & 4 & 32,000 & 86 \\
\hline Do & Am. Mg. Corp & $1 / 8$ & $1 \frac{1}{4}$ & 35,100 & 50,600 & 10 & 31,500 & 90 \\
\hline
\end{tabular}

a Each value is the average of 5 or more determinations.

\section{Preparation of Specimens}

Tests were made with 1/2-in. reduced-section standard ASTM tension specimens for sheet metals, except that the grip ends were 1 or $1 \frac{1 / 4}{4}$ in. wide, when possible, instead of the standard $3 / 4$ in., ${ }^{1}$ to minimize the failure of specimens as the result of stress corrosion around the bolt holes. Specimens of the sheet material machined with their long axes in and at right angles to the direction of rolling of the sheet, are designated hereafter as longitudinal (L) and transverse (T) specimens, respectively.

\section{Methods of Test}

Exposure tests were made on stressed specimens on the roof of the Northwest Building at this Bureau and in a marine atmosphere at Hampton Roads, Va. The stress-corrosion racks at Hampton Roads have been described in an earlier paper. $^{2}$ Those at this Bureau are shown in figure 1 , and the method of supporting the specimens, using flexure plates, is shown in figure 2. The ends of the specimens were gripped between two

\footnotetext{
1 One set of extrusions supplied by the Dow Chemical Co. had a rectangular cross section $3 / 4$ by $1 / 16$ in.

${ }^{2}$ H. L. Logan and H. Hessing, J. Research NBS 41, 69 (1948) RP1905.
}

pieces of $61 \mathrm{~S}-\mathrm{T} 6$ aluminum alloy bar by means of $3 / 8$-in. bolts of $17 \mathrm{~S}-\mathrm{T} 4$ aluminum alloy.

A stress-corrosion crack that developed in the reduced section of one of the specimens exposed in the weather is shown in figure 3 . Loose ${ }^{3}$ has suggested that a specimen should be considered to have failed when a stress-corrosion crack first appears. It was not possible with the personnel available to make the necessary inspections, at

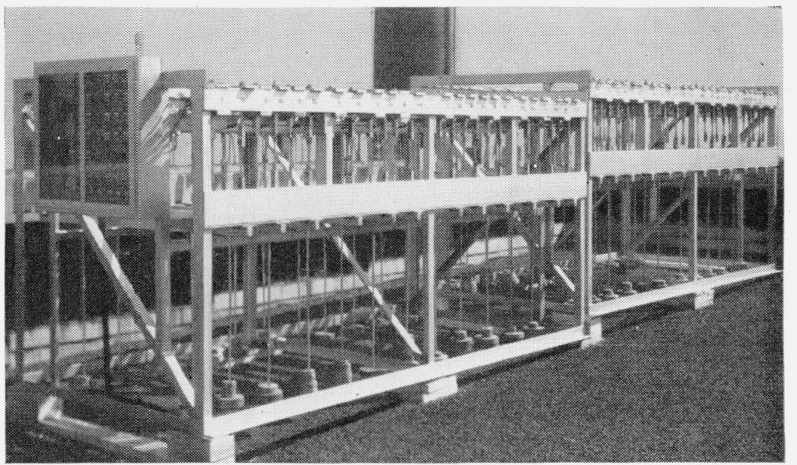

Figure 1. Stress-corrosion racks on the roof of the Northwest Building at the National Bureau of Standards.

Box at extreme left houses electric solenoid counters to determine exposure period of specimens to failure.

3 W. S. Loose, private communication, Dow Chemical Co., Midland, Mich. 


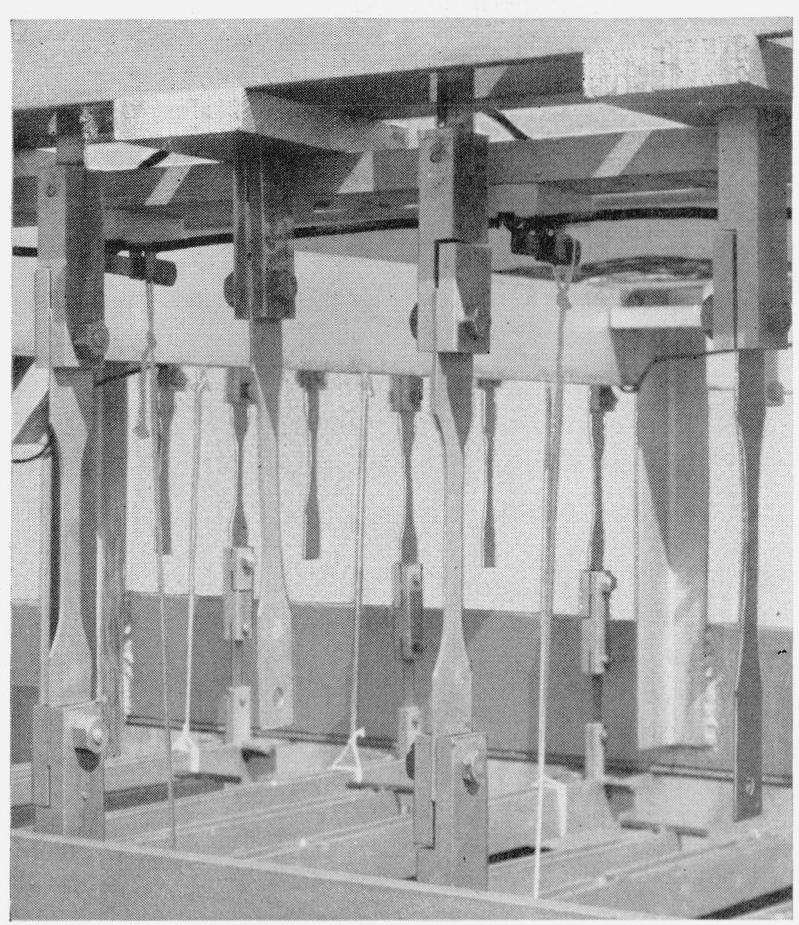

FIGURE 2. Method of supporting stress-corrosion specimens in rack shown in figure 1, using flexure plates above and below stressed specimens.

Fixtures were $61 \mathrm{~S}-\mathrm{T} 6$ aluminum alloy; bolts, 17S-T4 aluminum alloy. Knife switches were connected in series with solenoid counters shown in figure 1. Unstressed specimens were mounted adjacent to stressed specimens.

either weather exposure site, to determine when stress-corrosion cracks first appeared. Accordingly, the period to failure for the various specimens was determined as the interval between insertion and actual failure as recorded with electric solenoid counters that have been described in an earlier paper (see footnote 2).

At the time this investigation was begun other workers in the field were advocating the testing of sheet magnesium alloys in the laboratory by continuous immersion, under stress, in a sodium chloride-potassium chromate solution. "Threshold" stresses, defined as the maximum stresses that materials can withstand without failure for a fixed period of time when immersed in the corroding medium, were determined as a measure of the resistance of the alloys to stress corrosion.

The specimens tested in corroding solutions at this Bureau were immersed in glass cells and stressed by means of lever systems. The apparatus used in an earlier investigation (see footnote 2) was modified for these tests by the insertion, in the supports, of flexure plates (made of stainless steel sheet 1 inch wide by 0.020 inch thick), which are modifications of those used by Loose and Barbian (see footnote 3 ). The corrosive medium, a solution containing 3.5-percent $\mathrm{NaCl}$ and 2.0percent $\mathrm{K}_{2} \mathrm{CrO}_{4}$ was suggested by $\mathrm{R}$. H. Brown and G. F. Sager. ${ }^{4}$

Preliminary work in this laboratory and results obtained by other workers indicated that different values for the threshold stress were obtained depending on whether the specimens were loaded in tension before or after the solution was added. Work hardening of the specimens following loading and prior to adding the solution gave threshold stresses considerably higher than those obtained if the solution was added prior to the application of the major part of the load. Therefore all succeeding tests were made by loading the specimens. after the solution was added to the cells.

In order to supplement and possibly replace the continuous immersion test in the $\mathrm{NaCl}+$

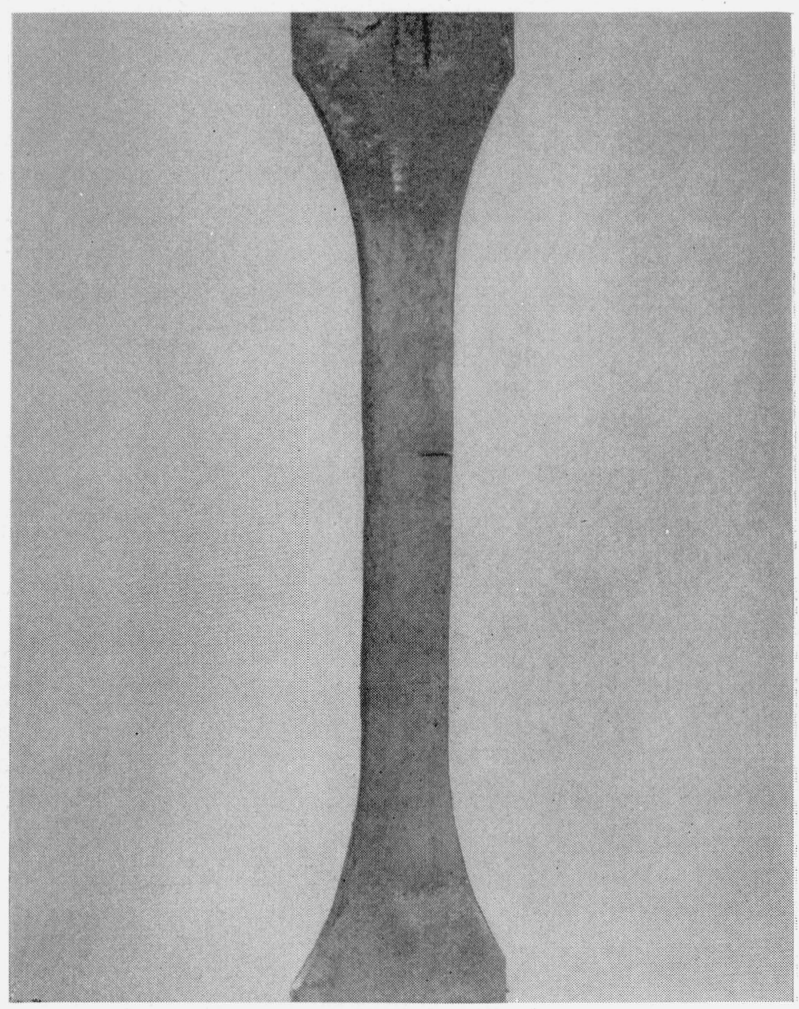

FiguRE 3. Stress-corrosion crack in specimen exposed to weather at the National Bureau of Standards.

\footnotetext{
${ }^{4}$ R. H. Brown, private communication (Aluminium Research Laboratories, New Kensington, $\mathrm{Pa}$.)
} 


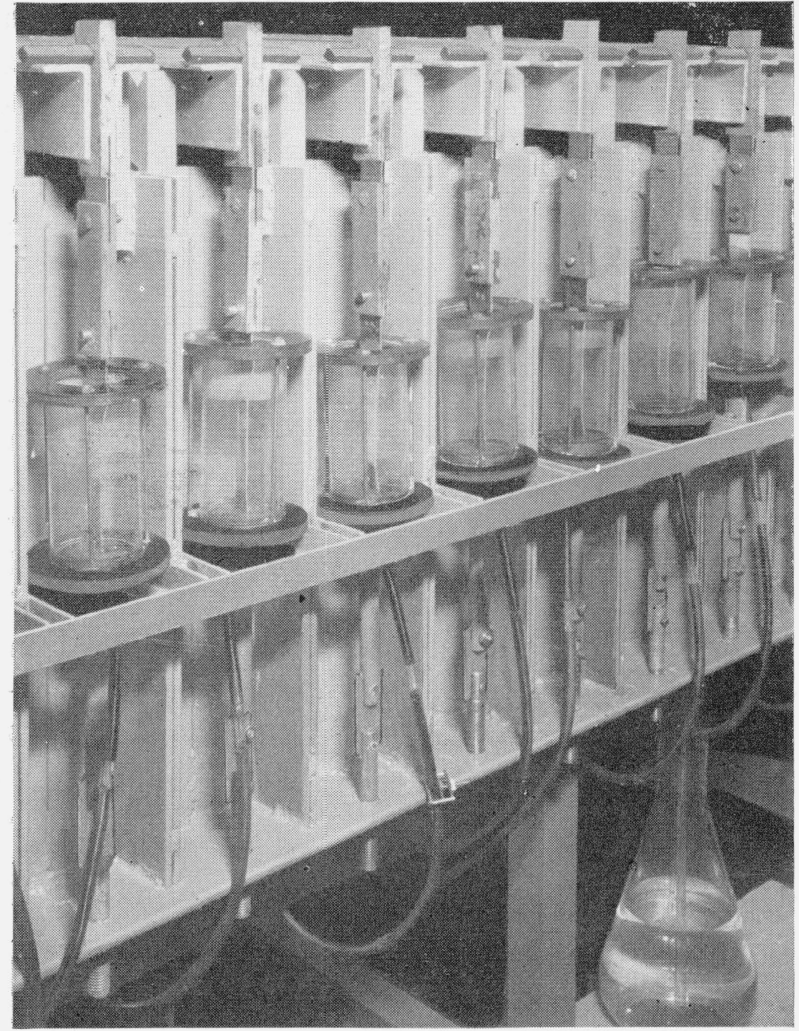

FIGURE 4. Specimens mounted for intermittent immersion tests in the laboratory.

Flexure plates were used in the supports above and below specimens, corrodent was raised from flasks (see lower right) to cells by means of compressed air.

$\mathrm{K}_{2} \mathrm{CrO}_{4}$ solution, intermittent immersion tests were made in various corrosive media at a constant temperature of $95^{\circ} \mathrm{F}\left(35^{\circ} \mathrm{C}\right)$. Specimens were mounted in cells as shown in figure 4 , and the corroding solution was raised into the cells by means of compressed air, wetting the specimens four times per hour. They were immersed for approximately $1 \mathrm{~min}$ and were permitted to dry for $14 \mathrm{~min}$ in each cycle. Intermittent immersion tests in a 3.5-percent sodium chloride solution produced such severe pitting of the specimens that stress-corrosion effects were obscured. Intermittent immersion in a 0.01 -percent $\mathrm{NaCl}$ solution or in a 0.01 normal $\mathrm{NaHCO}_{3}$ solution produced stress corrosion in magnesium alloys without producing general or pitting corrosion. Exposure periods to failure for a given alloy were approximately the same in either of these dilute solutions. However, the 0.01-percent $\mathrm{NaCl}$ solution was used for the balance of the intermittent immersion tests.

\section{Results and discussion of Stress-Corrosion Tests}

\section{Weather Exposure Tests}

The results of weather exposure tests on the various magnesium alloys are shown graphically in figures 5 to 9 , inclusive, and are given for the AZ31X-h material in table 6 . The plotted values in figure 5 generally represent the averages of three or more specimens exposed at a given stress. The results for individual M1-Clad specimens (exposed in the marine atmosphere), however, are shown as separate points in the figure. All the specimens exposed at a given stress, and duplicate specimens stressed differently were not necessarily exposed concurrently.

The data indicate that the M1-clad AZ31X-h material was more resistant to stress corrosion at high stresses than any of the other materials studied. Specimens of this material may be expected to have a life in a marine atmosphere of at least 500 days at a stress of $30,000 \mathrm{lb} / \mathrm{in} .^{2}$ The bare (unclad) material, exposed in a marine

TABle 6. Results of stress-corrosion tests on the AZ31X-h magnesium base alloy, 0.064 in. thick, exposed in the weather at the NBS, Washington, D. C. and at Hampton Roads, Va.

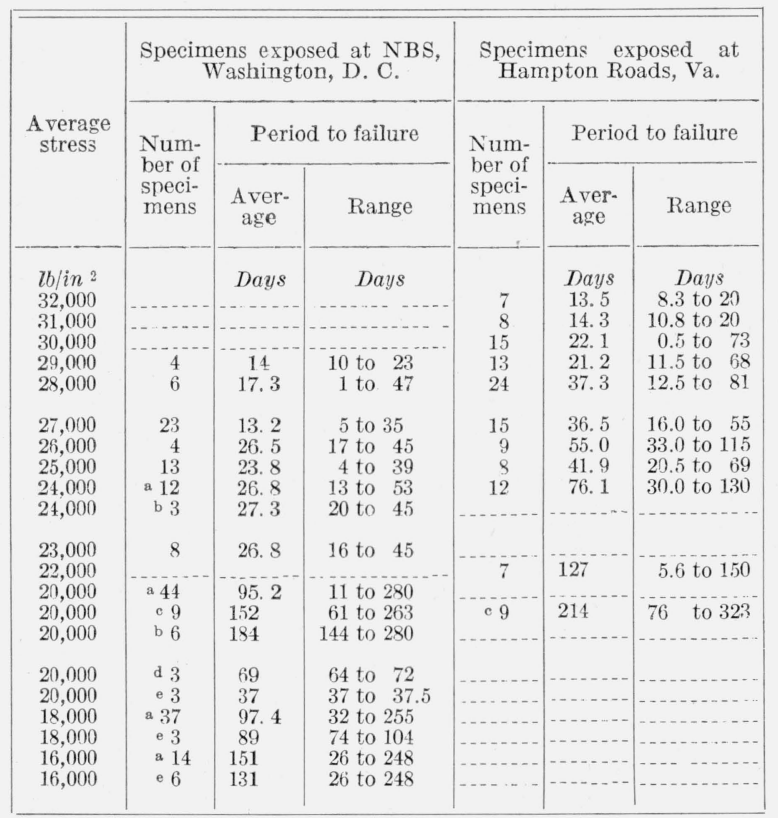

a Total number specimens tested under designated stress.

b Tested simultaneously with 0.125 -in. thick material.

c Tested simultaneously.

d Tested simultaneously with AZ51X and AZ61X material.

e Tested simultaneously with annealed material. 


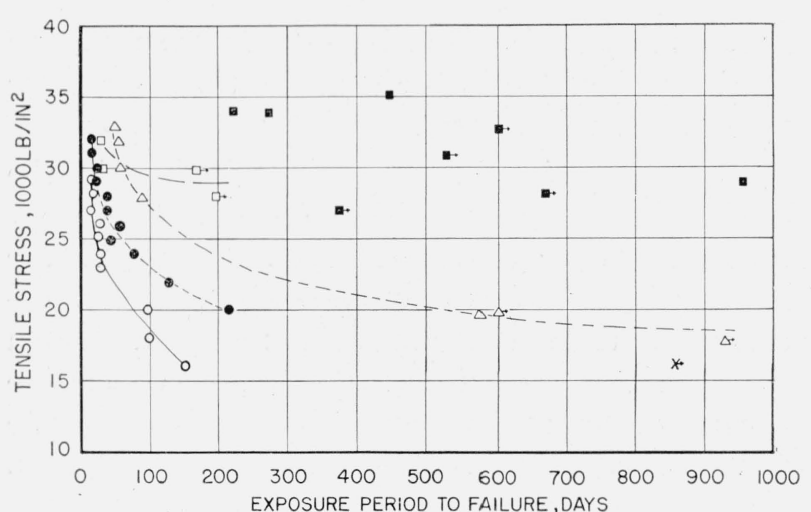

Figure 5. Stress-exposure period to failure curves for magnesium alloys exposed to the weather.

$\square$, M1 clad AZ31X-h sheet exposed at NBS; M1 clad AZ31X-h sheet exposed at Hampton Roads; $\triangle$, ZK60 extrusions exposed at NBS; $\bigcirc$, AZ31X-h sheet exposed at NBS; $\triangle \mathrm{Z} 31 \mathrm{X}-\mathrm{h}$ sheet exposed at Hampton Roads; X, M1-h sheet exposed at NBS; $\rightarrow$, specimen had not failed.

atmosphere, fractured under stresses of 20,000 $\mathrm{lb} / \mathrm{in}^{2}$ in an average period of 214 days. The clad specimen thickness was 0.080 in. compared to $0.064 \mathrm{in}$. for the bare alloy. This difference in thickness of the two materials would not be expected to produce more than a small difference in the expected life of specimens of the same material. The results, therefore, showed that the clad material was definitely more resistant to stress corrosion than the bare material.

Data shown in figure 5 and given in table 6 indicate that the exposure period to failure was generally shorter for specimens exposed under a given stress at the National Bureau of Standards site than for the same material exposed under the same stress in a marine atmosphere at Hampton Roads, Va. As a further check, 18 specimens were machined from the same sheet of the AZ$31 \mathrm{X}-\mathrm{h}$ alloy and were exposed to the weather on the same date and at the same stress, $20,000 \mathrm{lb} / \mathrm{in}^{2}$, one group at this Bureau, the other at Hampton Roads. The average period to failure for specimens exposed at the National Bureau of Standards was 152 days and at Hampton Roads, 214 days; ranges were 61 to 263 days and 76 to 323 days, respectively. No analysis of the atmosphere in the vicinity of the racks at this Bureau was made, but the smoke stack on an adjacent building, shown in figure 1, in all probability increased the corrosiveness of the atmosphere in the neighborhood of the stress-corrosion racks.

The results shown in figure 5 also indicate that the M1 sheet and the ZK-60 extruded materials (exposed at the National Bureau of Standards site) were relatively more resistant to stresscorrosion at moderate stresses than other bare materials studied. The M1 alloy specimens stressed at 16,000 lb/in. ${ }^{2}$ at the National Bureau of Standards site had not failed in 857 days. Specimens of the AZ31X-h alloy placed under test on the same date at the same stress failed after an average exposure period of 131 days (range 26 to 248 days). Two ZK-60 specimens exposed under stresses of $20,000 \mathrm{lb} / \mathrm{in}^{2}$ failed after 555 and 596 days exposure. Three specimens

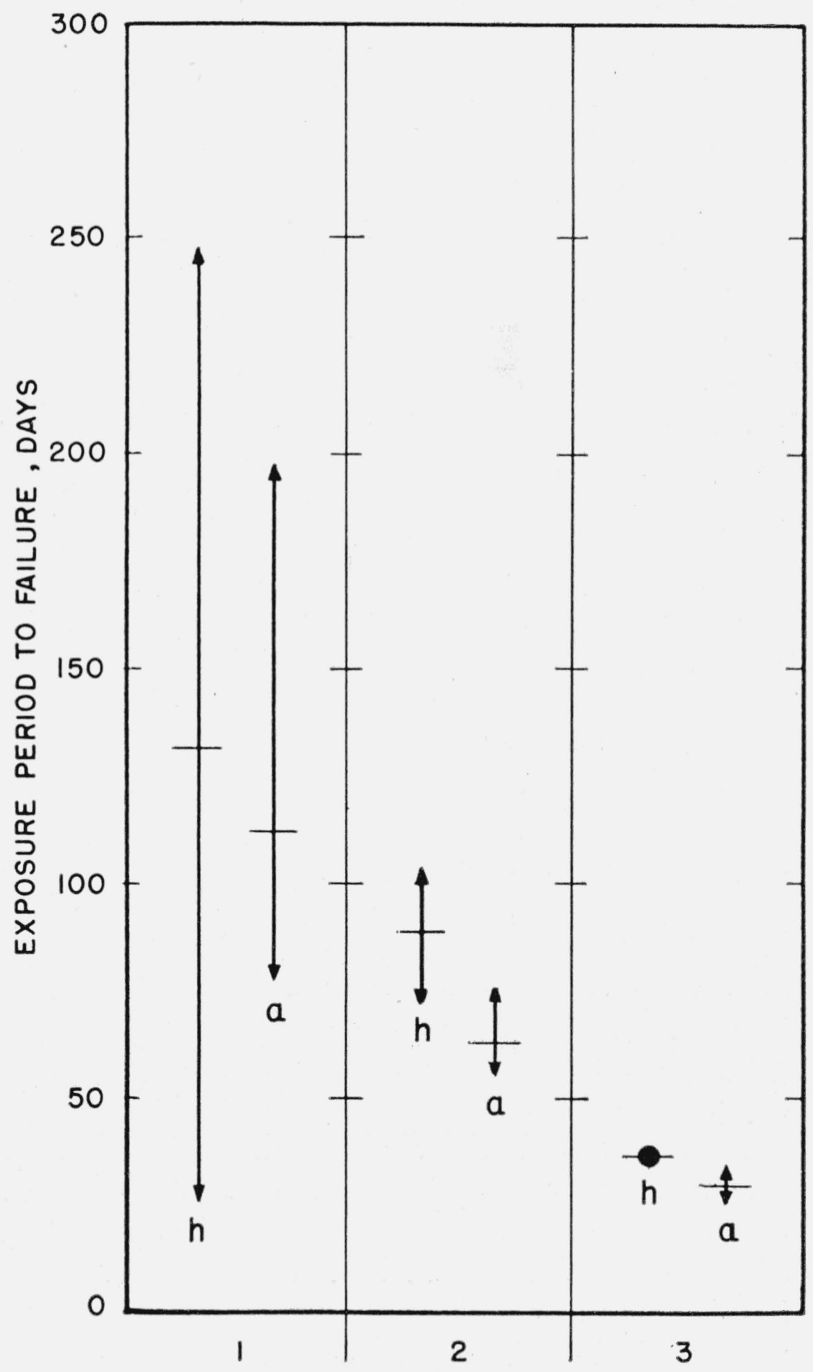

Figure 6. Resistance to stress corrosion of hardened $(\mathrm{h})$ and annealed (a) AZ31X sheet materials exposed to the weather at the National Bureau of Standards site at three different stresses.

1, Strees, 16,000 lb/in.2 2 2, stress, 18,000 lb/in..$^{2} ; 3$, stress, 20,000 lb/in.2; +, average value; $\longleftrightarrow$, range. 


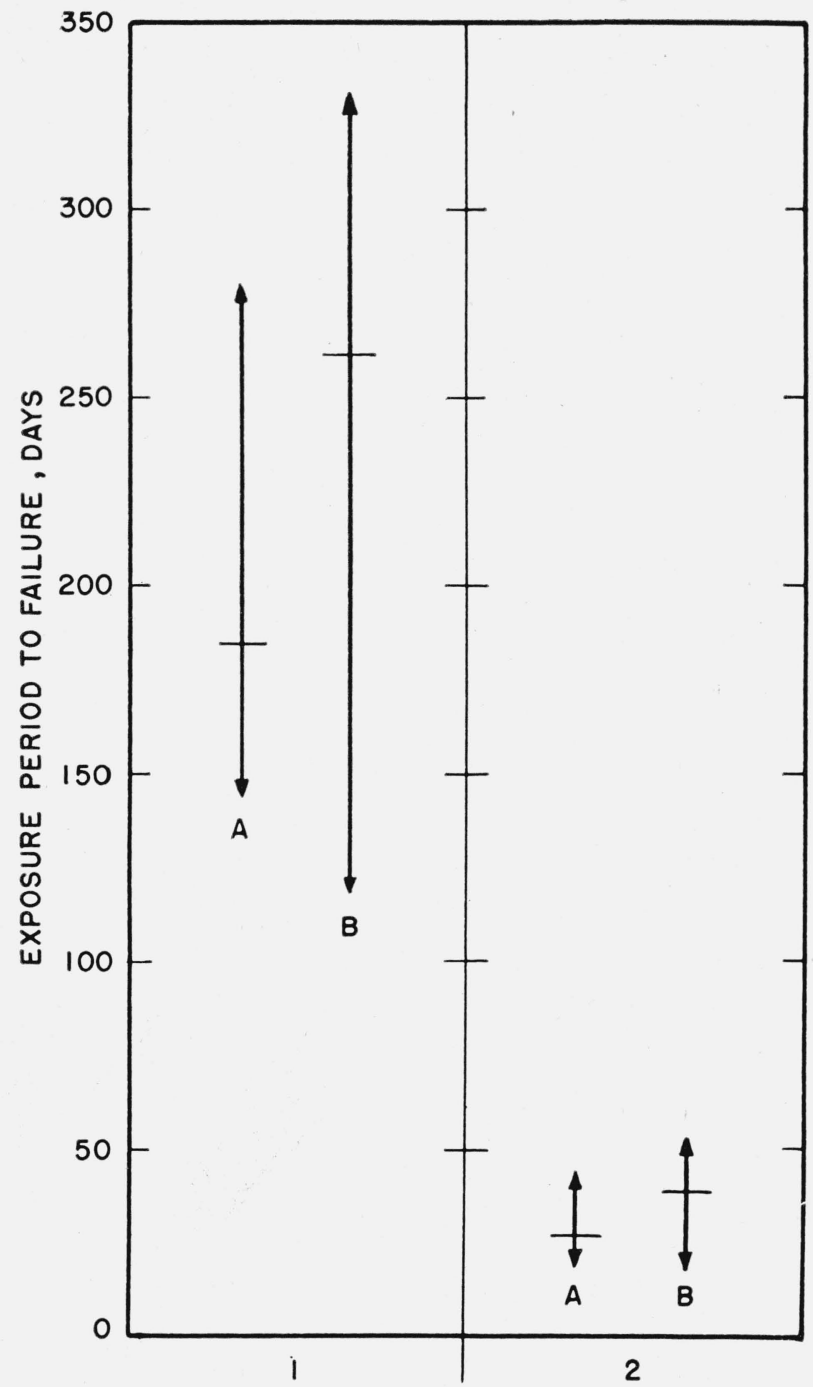

FiguRE 7. Effect of specimen thickness on the resistance of the $A Z 31 X-\mathrm{h}$ material to stress corrosion.

1. Stress $20,000 \mathrm{lb} / \mathrm{in} .{ }^{2} ; 2$, stress, $24,000 \mathrm{lb} / \mathrm{in} .{ }^{2} ; \quad+$, average value; $\leftarrow$, range. A, 0.064-in. material; B, 0.125-in. material.

exposed at the same stress had not failed in 600 days.

It was noted that, although an occasional specimen failed during a period of dry weather, most failures occurred during the drying period after the specimens had been wet by rain. This fact is believed to account, at least in part, for the wide variations in exposure periods required for failure, for specimens subjected to the same stress, seen in table 6 and shown graphically in figures 6 to 9 inclusive. Because of the increased number of failures occuring after rain had fallen, direct comparisons of weather exposure results, shown in figures 6 to 9 , inclusive, were made on specimens inserted in the racks on the same dates under the same stresses.

Results obtained on the AZ31X alloy in the annealed and rolled conditions (see fig. 6) indicated that for stresses of 18,000 and $20,000 \mathrm{lb} / \mathrm{in} .^{2}$ the hardened material was more resistant to stresscorrosion than the annealed material. Data obtained at $16,000 \mathrm{lb} / \mathrm{in}^{2}{ }^{2}$ are not so conclusive because of the small difference between the average values and the large scatter in the observed values.

The effect of specimen thickness on the resistance of the AZ31X-h material to stress corrosion is shown in figure 7 . The average period to failure for the 0.125 -in. thick material was greater than that for the 0.064-in. thick material. However, the scatter was such that it is not possible to say that any particular 0.064-in. specimen would fail

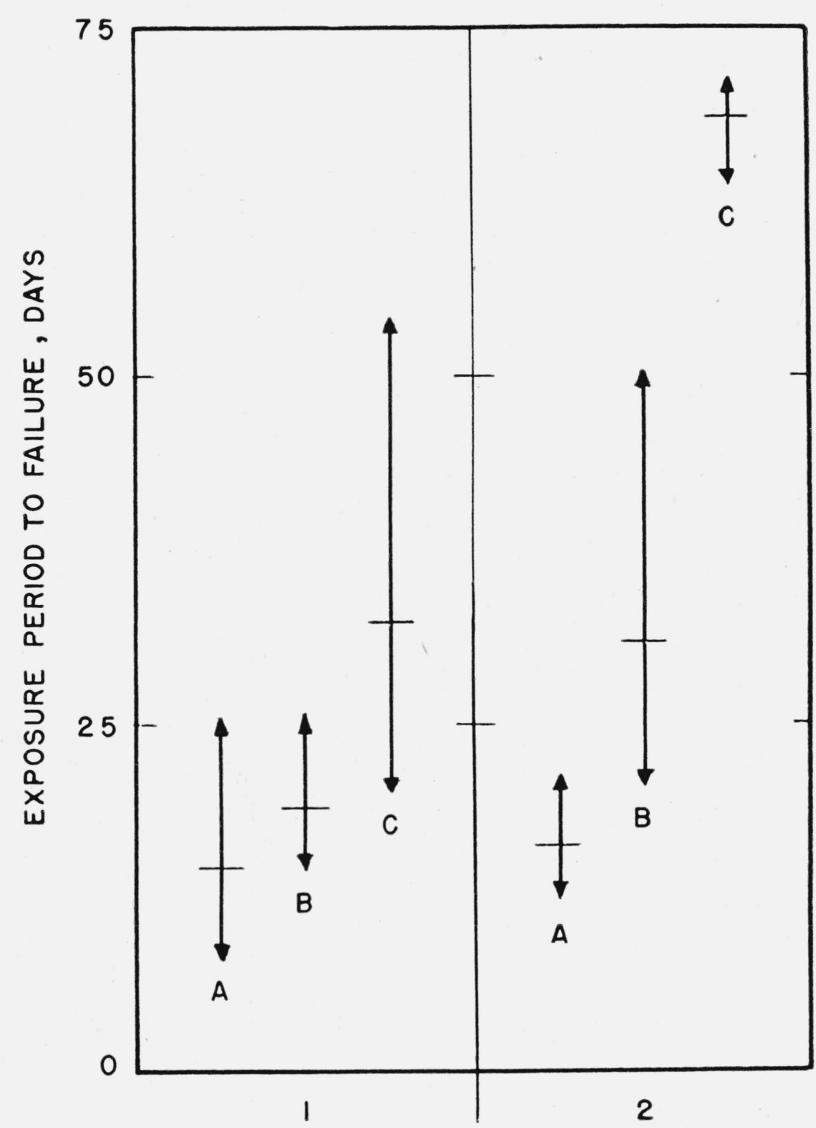

Figure 8. Effect of aluminum content on the stress corrosion behavior of three magnesium alloys.

AZ61X contained 6.5\% Al; AZ51X, 5.0\% Al; AZ31X, 3.0\% Al. 1, Intermittent immersion in $0.01 \% \mathrm{NaCl}$ solution; $\mathrm{A}, \mathrm{AZ} 61 \mathrm{X}-\mathrm{h} ; \mathrm{B}, \mathrm{AZ} 51 \mathrm{X}-\mathrm{h} ; \mathrm{C}$, AZ31X-h. 2, Weather exposure NBS; A, AZ61X-h; B, AZ51X-h; C, AZ31X-h. Stress $=20,000 \mathrm{lb} /$ in. $^{2} ;+$, average value; $\leftarrow$, range. 


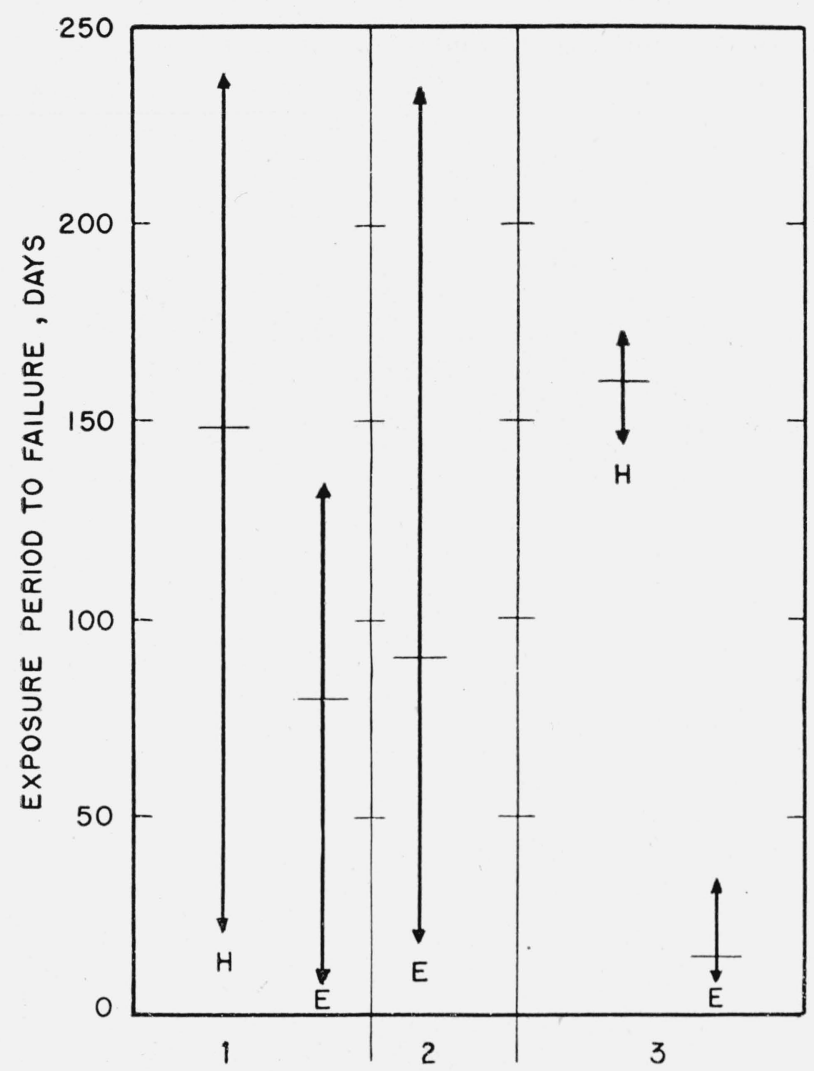

Figure 9. Resistance to stress corrosion of two extruded magnesium alloys under stress of $20,000 \mathrm{lb} / \mathrm{in}^{2}$.

1, AZ80X, 2, AZ61X; weather exposure. 3, AZ80X, intermittent immersion. -+ , average value; $\longleftrightarrow$, range. $\mathrm{H}=$ heat treated and aged; $\mathrm{E}=$ as extruded.

in a shorter period of time than a given 0.125 -in. thick specimen.

The results discussed above for the M1-h and AZ31X-h material and the results of tests on the AZ31X-h, AZ51X-h, and AZ61X-h alloys, shown at the right in figure 8 indicate that at moderate stresses the resistance of the wrought magnesium alloys to stress-corrosion decreased with increased aluminum content up to about 6.5 percent of aluminum.

Although it was badly discolored, the ZK-60 extruded alloy, as indicated above, was the most resistant to stress corrosion of any of the extruded materials studied. The average periods to failure and the ranges for the AZ80X alloy exposed as extruded and after heat treatment and aging, and for the AZ61X extruded alloy (4 to 6 specimens of each alloy) all exposed in the weather at this Bureau under stress of $20,000 \mathrm{lb} / \mathrm{in}^{2}{ }^{2}$ are shown graphically in figure 9 . It can be seen that the average period to failure of the heat-treated and aged AZ80X material was greater than the maximum value for the material as extruded. Because of the scatter obtained with both materials, it was difficult to say whether the AZ61X was more susceptible to stress-corrosion than the AZ80X-H'TA alloy.

Ultimate tensile strengths of the bare AZ31X-h, the ZK-60, and the AZ80X alloys, determined after specimens had been exposed unstressed in the weather at this Bureau for periods of 750 to 800 days, were at least 94 percent of those of the unexposed material. Changes in ductility (measured in percentage elongation in 2 in.) varied with the different alloys; values for the exposed ZK-60 and AZ31X-h materials were 85 percent or more of those of the unexposed materials. No elongation data were obtained on the AZ80X material.

The decrease in the ultimate tensile strength of M1-clad AZ31X-h material exposed unstressed for periods up to 960 days in a marine atmosphere was small; the tensile strength was 95 percent or more of that of the original material. Elongations, however, were reduced to 25 to 50 percent of those of the unexposed material.

The maximum exposure periods for the AZ61X-h and AZ51X-h materials, exposed unstressed at this Bureau, were 50 days and 22 days, respectively. Ultimate tensile strengths were 94 percent or more of those of the unexposed materials; elongations of the AZ61X-h and AZ51X-h materials were 70 percent or more and 85 percent or more, respectively, of those of the unexposed materials.

The data indicate that: (1) the M1-clad AZ31X-h alloy is relatively immune to stress corrosion at stresses of about $30,000 \mathrm{lb} / \mathrm{in}^{2}{ }^{2}$ (2) The ZK-60 and the M1-h alloys are relatively immune to stress corrosion at stresses below 20,000 and 16,000 $\mathrm{lb} / \mathrm{in}^{2}{ }^{2}$, respectively. The tensile properties of the M1 alloy were lower than those of other alloys studied. Hence it was exposed only at a stress of $16,000 \mathrm{lb} / \mathrm{in}^{2}$ on longitudinal specimens. The AZ51X, AZ61X, and AZ80X alloys were all susceptible to stress corrosion in the weather when subjected to stresses of $20,000 \mathrm{lb} / \mathrm{in} .^{2}$ These alloys were not exposed in the weather at lower stresses. (3) The AZ31X-h alloy was susceptible . to stress-corrosion in the weather at stresses of 16,000 or more $\mathrm{lb} / \mathrm{in}^{2}$ 


\section{Continuous Immersion Tests in the $\mathrm{NaCl}+\mathrm{K}_{2} \mathrm{CrO}_{4}$ Solution}

The curve in figure 10 shows the relationship between the stress and the exposure period to failure for specimens of annealed AZ31X material. The stresses that the materials would withstand for $24 \mathrm{hr}$ or longer in the $\mathrm{NaCl}+\mathrm{K}_{2} \mathrm{CrO}_{4}$ solution, as determined from curves of this type, are defined as the threshold stresses. It was suggested that such a test could be used as an accelerated test to evaluate the resistance of magnesium alloys to stress corrosion, if a relationship could be established between the threshold values and the ultimate tensile strengths or yield strengths of the material or the long-time stress-corrosion data.

Threshold stresses for the various sheet and extruded alloys, given in tables 2 to 5 , inclusive, show that with the exception of 0.064 -in. thick AZ61X-h sheet material supplied by the American Magnesium Corp. the threshold stresses were greater than 75 percent of the yield strength of the material. The threshold stresses (in terms of yield strengths) of the annealed AZ61X alloy were generally higher than those of the hardened (rolled) material. The threshold stresses of other materials studied, in percentages of the yield strength, were generally approximately the same whether the material was in the annealed or rolled conditions.

The threshold stresses obtained in the $\mathrm{NaCl}+$ $\mathrm{K}_{2} \mathrm{CrO}_{4}$ solution do not indicate the minimum

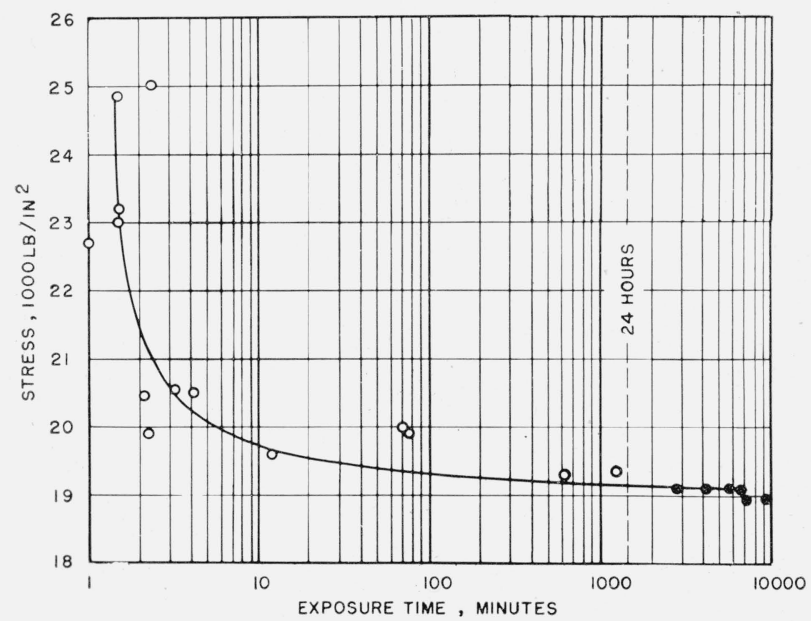

Figure 10. Stress-exposure behavior of AZ31X-a specimens, immersed continuously in a $\mathrm{NaCl}+\mathrm{K}_{2} \mathrm{CrO}_{4}$ solution.

$$
\bigcirc \text {, specimen failed; specimen did not fail. }
$$

stresses at which the material will fail by stresscorrosion cracking in the weather. Furthermore, relative susceptibilities of some of the alloys, as determined from threshold stresses given in tables 2 to 5 do not agree with weather exposure data shown in figures 8 and 9 .

\section{Intermittent Immersion Tests in the 0.01-Percent $\mathrm{NaCl}$ Solution}

The results of intermittent immersion stresscorrosion tests on the AZ61X, AZ51X, and AZ31X alloys (all in the rolled condition) are shown graphically in figure 8 (left). For comparison, results of weather exposure tests on these alloys are shown at the right in figure 8 . The resistance to stress corrosion of the three materials was in the same order in the intermittent immersion tests in the 0.01 -percent $\mathrm{NaCl}$ solution as in the weather exposure tests.

The results of intermittent immersion tests in the 0.01-percent $\mathrm{NaCl}$ solution for the AZ80X alloy after heat treatment and aging and for the alloy as extruded are shown graphically in figure 9. The results are in qualitative agreement with those obtained in weather exposure tests for this alloy in the two conditions.

There were insufficient data from intermittent immersion tests on the other materials studied to determine whether these results show close correlation with weather exposure data.

\section{Discussion of Laboratory Accelerated Tests}

It was pointed out in section. III, 2, that continuous immersion tests in the $\mathrm{NaCl}+\mathrm{K}_{2} \mathrm{CrO}_{4}$ solution have two drawbacks. First, threshold stresses (stresses below which stress-corrosion fractures did not occur in the $\mathrm{NaCl}+\mathrm{K}_{2} \mathrm{CrO}_{4}$ solution) were much higher than those obtained for the same alloy in the weather. Second and more important, the correlation was poor between predictions of relative susceptibilities of various magnesium alloys, made from the results of this test and the results of weather exposure data.

There was general agreement between the results of intermittent immersion and weather exposure tests on the AZ31X-h, AZ51X-h, and AZ61X-h alloys as was indicated in section III, 3. These results, and the limited results obtained on other materials, indicate that intermittent immersion tests in a dilute chloride solution are a better 
laboratory means of predicting the relative susceptibilities of magnesium alloys to stress corrosion in the atmosphere than is continuous immersion in a sodium chloride-potassium chromate solution.

\section{Summary}

1. Stress-corrosion tests were made on M1, bare and clad AZ31X, AZ51X, AZ61X, AZ80X, and ZK-60 wrought magnesium base alloys. Stressexposure period to failure results were obtained both in weather exposure and in two types of laboratory tests.

2. The decrease in tensile properties of unstressed specimens exposed at the National Bureau of Standards site was small.

3. The M1-clad AZ31X-h alloy was resistant to stress corrosion in a marine atmosphere at stresses up to $30,000 \mathrm{lb} / \mathrm{in}^{2}$

4. The bare AZ31X alloy was susceptible to stress corrosion in the weather at stresses of 16,000 $\mathrm{lb} / \mathrm{in}^{2}{ }^{2}$ or more.

5. The sheet M1 and the extruded Dow ZK-60 alloys were resistant to stress corrosion in weather exposure tests at stresses up to 16,000 and 20,000 $\mathrm{lb} / \mathrm{in}^{2}$, respectively.
6. The AZ51X, AZ61X, and AZ80X alloys were all susceptible to stress corrosion in the weather when subjected to stresses of $20,000 \mathrm{lb} / \mathrm{in}^{2}$ These alloys were not tested at lower stresses.

7. The susceptibility of magnesium base alloys to stress corrosion increased with the aluminum content up to approximately 6.5-percent aluminum.

8. Results of intermittent immersion laboratory tests, using a 0.01-percent $\mathrm{NaCl}$ solution as a corrodent, were in better agreement with those obtained in weather exposure than were those obtained by continuous immersion in a 3.5 -percent $\mathrm{NaCl}+2.0$-percent $\mathrm{K}_{2} \mathrm{CrO}_{4}$ solution.

The cooperation of Fred M. Reinhart and the late Willard H. Mutchler of the National Bureau of Standards, and of Lieutenants C. A. Snavely and M. Franklin, of the Naval Air Station, Hampton Roads, Va., in sccuring the weather exposure data at Hampton Roads is appreciated. Houston Babb and Thomas P. Royston, Jr., assisted in obtaining the data at the National Bureau of Standards.

Washington, September 22, 1949. 